\title{
Isolation, Identification and Antifungal Activities of Streptomyces aureoverticillatus HN6
}

\author{
Lanying Wang', Mengyu Xing ${ }^{1}$, Rong $\mathrm{Di}^{2 *}$ and Yanping Luo ${ }^{1 *}$
}

${ }^{1}$ Key Laboratory of Protection and Development Utilization of Tropical Crop Germplasm Resources, Ministry of Education, College of Environment and Plant Protection, Hainan University, Haikou, Hainan, 570228, P. R. China

${ }^{2}$ Department of Plant Biology and Pathology, School of Environmental and Biological Sciences, Rutgers, the State University of New Jersey, 59 Dudley Road, New Brunswick, New Jersey, 08901, USA

\begin{abstract}
Banana Fusarium wilt caused by Fusarium oxysporum f. sp. cubense race 4 (FOC4) is destroying numerous banana plantations in southern China. In order to select an effective biocontrol agent for this devastating disease, eighty nine actinomycete isolates were collected from soil samples in the Botanical Garden of Chinese Academy of Tropical Agricultural Sciences in the tropical Hainan Province, China. These isolates were evaluated for their antagonistic activity against FOC4. Our results showed that eight isolates exhibited strong anti-FOC4 activity. One of the isolates, HN6, resulted in an inhibition zone of $35 \mathrm{~mm}$ in diameter in the antagonistic test. The mycelia of HN6 were extracted with methanol, and the extract was tested against eight indicator pathogens by the mycelium growth rate method. The HN6 extract demonstrated broad-spectrum antifungal activity, with an $\mathrm{EC}_{50}$ less than 0.08 $\mathrm{mg} / \mathrm{ml}$. Based on the morphological, biochemical, physiological and cultural characteristics and the 16S rRNA gene sequence, the HN6 isolate was identified as Streptomyces aureoverticillatus. HN6 isolate can be potentially developed into a biocontrol agent for banana Fusarium wilt and other plant diseases.
\end{abstract}

Keywords: Banana Fusarium wilt; Actinomycete; Antifungal Activity; Streptomyces aureoverticillatus; Isolate HN6

\section{Introduction}

Banana Fusarium wilt, also called banana Panama wilt, is a destructive disease that affects bananas in tropical and subtropical areas worldwide. Fusarium oxysporum f. sp. cubense race 4 (FOC4) is one of the major pathogens causing banana Fusarium wilt [1]. Banana is one of the most important agricultural crops in the world, many disease management strategies have been applied to control this disease including resistant cultivars, fungicide application, crop rotation and soil management [2]. However, FOC4 is still expanding at a speed of $30-50 \mathrm{~km}$ each year, destroying numerous banana plantations in south China [3].

Extensive application of chemical pesticides in agriculture has led to numerous side effects for the environment and human health. In search for environmentally friendly and safe substitute, biological pesticides are more appropriate compared to chemical pesticides. Actinomycetes play an important role in the discovery of antibiotics, antitumor agents and biopesticides [4-7]. Actinomycetes produce a wide range of bioactive secondary metabolites that are known to have anticancer, antibacterial, antifungal, antialgal, antimalarial and antiinflammatory activities [8]. Approximately two-thirds of the naturally occurring antibiotics have been isolated from actinomycetes [9]. Soil from the tropical Hainan Island (Hainan Province) in China presents a unique ground for the discovery of microbial inhabitants with extensive biodiversities that have been found to produce many biologically active natural products $[7,10]$. In order to identify biological control agents against FOC4, we isolated and screened eighty nine actinomycetes from soil samples in the Botanical Garden on Hainan Island, China. These isolates were tested for their antagonistic activities against FOC4 and for their broad-spectrum antifungal activities against totally eight indicator plant pathogens. Out of these isolates, HN6 was shown to exert the highest anti-FOC4 activity. HN6 was identified to belong to the Streptomyces genus based on its morphological, biochemical, physiological and cultural characteristics and its 16S rRNA gene sequence.

\section{Materials and Methods}

\section{Sample collection and processing}

Soil samples were collected from the Botanical Garden of Chinese Academy of Tropical Agricultural Sciences in Hainan Province (Hainan Island) in China. They were collected from 10-15 cm depth in soil, placed into sterile plastic bags and transported aseptically to the laboratory. The collected soil samples were mixed thoroughly and passed through a $2 \mathrm{~mm}$ sieve to remove gravel and debris. They were air dried for one week at room temperature.

\section{Isolation of actinomycetes}

To prepare soil suspension, $5 \mathrm{~g}$ of soil sample was transferred into a sterile bottle. After adding $45 \mathrm{ml}$ of sterile distilled water to the sample, the bottle was shaken for $30 \mathrm{~min}$. Five sets of ten-fold serial dilutions were prepared from the original supernatant, and $0.1 \mathrm{ml}$

*Corresponding authors: Yanping Luo, Key Laboratory of Protection and Development Utilization of Tropical Crop Germplasm Resources, Ministry of Education, College of Environment and Plant Protection, Hainan University, Haikou, Hainan, 570228, P. R. China, Tel: +86-898-66192915; Fax: +86-89866192915; E-mail: yanpluo@126.com

Rong Di, Department of Plant Biology and Pathology, School of Environmental and Biological Sciences, Rutgers, the State University of New Jersey, 59 Dudley Road, New Brunswick, New Jersey, 08901, USA Tel: +1-848-932-6350; Fax: 732-9329377; E-mail: di@aesop.rutgers.edu

Received June 15, 2015; Accepted June 24, 2015; Published June 28, 2015

Citation: Wang L, Xing M, Di R, Luo Y (2015) Isolation, Identification and Antifungal Activities of Streptomyces aureoverticillatus HN6. J Plant Pathol Microb 6: 281 doi:10.4172/2157-7471.1000281

Copyright: ( 2015 Wang L, et al. This is an open-access article distributed under the terms of the Creative Commons Attribution License, which permits unrestricted use, distribution, and reproduction in any medium, provided the original author and source are credited. 
of each diluted sample was used to spread on Gause's no.1 synthetic medium aseptically [11]. Each sample was spread onto three plates and incubated at $28^{\circ} \mathrm{C}$ for $5-10$ days. The plates were observed periodically for the growth of actinomycetes. The pure colonies were selected, isolated and maintained in Gause's no. 1 synthetic medium at $4^{\circ} \mathrm{C}$ for subsequent studies.

\section{Screening for FOC4 antagonistic actinomycetes}

The isolated actinomycetes were inoculated into Gause's no.1 medium and incubated at room temperature for 5 days. Actinomycete cakes $(\Phi=5 \mathrm{~mm})$ were obtained and inoculated onto one side of the PDA (potato dextrose agar) plate. The ATCC76255 strain of Fusarium oxysporum f. sp. cubense race 4 (FOC4) was inoculated onto the other side of the PDA plate, with a distance of $4 \mathrm{~cm}$. They were cultured at $25^{\circ} \mathrm{C}$ for 5 days. The antagonistic belt (inhibition zone) was recorded by measuring the distance $(\mathrm{mm})$ between the edge of the fungal mycelium and the actinomycete cakes. All isolates were tested in three independent replicates. Of all the isolates, eight of the best antagonistic actinomycete isolates were selected, identified macroscopically and microscopically by Gram's staining and used for further studies.

\section{Characterization of isolate HN6}

The selected actinomycete isolate HN6 was further identified by morphological, biochemical and physiological characterization and by $16 \mathrm{~S}$ rRNA gene sequencing. The morphological characteristics for colony, aerial and substrate mycelia and spores were studied after culturing the individual isolates on Gause's no. 1 medium at $28^{\circ} \mathrm{C}$ for at least 7 days [12]. HN6 was investigated for various physiological and biochemical properties including the utilization of cellulose, inositol, mannitol and seven different sugars as carbon source, starch hydrolysis, glutin liquefaction, litmus milk reaction and $\mathrm{H}_{2} \mathrm{~S}$ production $[13,14]$. The cell wall type and whole-cell sugar analysis for chemical grouping of HN6 was performed as previously described [15].

The 16S rRNA gene was amplified by PCR with Taq DNA polymerase and the conserved primers $\mathrm{F}$ (5'-AGAGTTTGATCCTGGCTCAG-3') and R (5'-ACGGCTACCTTGTTACGACTT-3') [16]. The conditions for thermal cycling were as follows: denaturation of the fungal DNA at $95^{\circ} \mathrm{C}$ for $5 \mathrm{~min}$ followed by 35 cycles at $94^{\circ} \mathrm{C}$ for $1 \mathrm{~min}$, primer annealing at $50^{\circ} \mathrm{C}$ for $1 \mathrm{~min}$ and DNA elongation at $72^{\circ} \mathrm{C}$ for $2 \mathrm{~min}$. At the end of the PCR reaction, the reaction mixture was held at $72^{\circ} \mathrm{C}$ for $10 \mathrm{~min}$ [17]. PCR amplification was detected by agarose gel electrophoresis in Shanghai Yingjun Biotechnology Co., Ltd. The PCR product obtained was sequenced by a Sanger-based, automated sequencer (Applied Biosystems). The sequence was compared for similarity with the reference species of bacteria in the genomic databank, using the NCBI BLAST available at http://www.ncbinlm-nih.gov/. The phylogenetic tree was constructed by neighbor-joining method in Mega4.0 software [18].

\section{Antifungal activities of HN6 methanol extract}

The fermentation medium for the antagonistic actinomycete HN6 isolate included soluble starch $9.0 \mathrm{~g}$, soybean meal $3.0 \mathrm{~g}, \mathrm{~K}_{2} \mathrm{HPO}_{4} 0.5 \mathrm{~g}$, $\mathrm{MgSO}_{4} \cdot 7 \mathrm{H}_{2} \mathrm{O} 0.5 \mathrm{~g}, \mathrm{FeSO}_{4} \cdot 7 \mathrm{H}_{2} \mathrm{O} 0.01 \mathrm{~g}, \mathrm{NaCl} 0.5 \mathrm{~g}$ and distilled water in $1000 \mathrm{ml}, \mathrm{pH}$ 6.0. After the fermentation growth, the actinomycete biomass was harvested by centrifugation at $5.2 \mathrm{~g}$ at $20^{\circ} \mathrm{C}$ for 10 minutes. The mycelia were washed three times with sterile distilled water under aseptic conditions. They were then resuspended in a small amount of methanol and ground with mortar and pestle and broken under $20 \mathrm{KHZ}$ ultrasonic waves for $5 \mathrm{~min}$. Methanol was added to the ground cells in the ratio of $1: 1(\mathrm{w} / \mathrm{v})$ and the mixture was shaken vigorously overnight.
The extract was then filtered through a blotting paper. The filtrate was evaporated using a rotary evaporator at $50^{\circ} \mathrm{C}$. The concentrated extract was then transferred into glass screw-capped tubes and stored at $4^{\circ} \mathrm{C}$ for further use.

The HN6 extract was diluted with methanol to $6.60,1.32,0.66,0.66$, $0.132,0.066,0.044 \mathrm{mg} / \mathrm{ml}$ preparations. One milliliter of each extract was added to $19 \mathrm{ml} \mathrm{PDA}$ medium at $45^{\circ} \mathrm{C}$, and quickly portioned into three Petri dishes $(\Phi=5 \mathrm{~mm})$. Each concentration was replicated three times. One milliliter of methanol adding into $19 \mathrm{ml}$ PDA medium was used as control.

To conduct mycelium growth rate test eight indicator plant pathogens Fusarium oxysporum f. sp. cubense race 4 (ATCC 76255), Botryodiplodia theobromae (ATCC 10936), Colletotrichum gloeosporioides (ATCC 20358), Colletotrichum gloeosporioides Penz (ATCC 16330), Colletotrichum musae (ATCC 96167), Corynespora cassiicola (ATCC 36294), Periconia circinata (ATCC 32727) and Rhizoctonia solani (ATCC 58938) were grown on PDA Petri dishes. The fungal mycelia were taken from the periphery of stock cultures $[19,20]$. Plugs of mycelia were removed with a $5 \mathrm{~mm}$ cork borer from the advancing margin of the fungal colonies, placed in the center of each PDA Petri dish containing the HN6 methanol extract at different concentrations, with the mycelia facing the medium. The cultures were incubated at $25 \pm 2^{\circ} \mathrm{C}$ for 3 days. Fungal toxicity was expressed by the inhibitory percentage of the mycelia growth compared to the control. The colony diameter was measured in millimeters, excluding the plug. An average was taken from three measurements made on each Petri dish.

\section{Results}

\section{Isolation and screening for antagonistic actinomycetes}

Eighty nine actinomycetes were isolated from soil samples from the Botanical Garden of tropical Hainan Province, China by the gradient dilution method, and identified by their morphology. To study their antagonistic activities, these isolates were tested by the antagonistic belt (inhibition zone) method against Fusarium oxysporum f. sp. cubense (FOC4), the causal agent of banana Fusarium wilt. Out of 89 actinomycetes, 8 isolates including HN3, HN6, HN14, HN24, HN29, HN59, HN62, HN75 showed strong inhibition of FOC4 growth, with the diameters of inhibition zones of more than $18 \mathrm{~mm}$ (Table 1). HN6 exhibited the strongest antagonistic activity, with an inhibition zone of $35 \mathrm{~mm}$.

\section{Morphological, physiological and biochemical characteristics of HN6 isolate}

Due to the strong antagonistic activity against FOC4, HN6 isolate was selected for further studies on its morphological, physiological and biochemical characteristics.

\begin{tabular}{|c|c|}
\hline Isolate & Inhibition zone $\mathbf{( m m})^{*}$ \\
\hline HN3 & $20 \pm 0.8$ \\
\hline HN6 & $35 \pm 0.6$ \\
\hline HN14 & $18 \pm 1.2$ \\
\hline HN24 & $19 \pm 1.0$ \\
\hline HN29 & $20 \pm 1.1$ \\
\hline HN59 & $19 \pm 0.9$ \\
\hline HN62 & $18 \pm 1.4$ \\
\hline HN75 & $18 \pm 1.2$ \\
\hline
\end{tabular}

Table 1: Inhibiting zones of 8 actinomycete isolates against FOC4 five days after incubation. *Values are means of three replications. 
Citation: Wang L, Xing M, Di R, Luo Y (2015) Isolation, Identification and Antifungal Activities of Streptomyces aureoverticillatus HN6. J Plant Pathol Microb 6: 281. doi:10.4172/2157-7471.1000281

Page 3 of 5

When HN6 was cultured on different media, its aerial mycelium and substrate mycelium displayed different colors (Table 2). The morphology of HN6 spore and mycelium was observed on Gause's no.1 medium at $28^{\circ} \mathrm{C}$. The colonies were small. The aerial mycelia were white in color, and the substrate mycelia were beige. They did not produce diffusible pigment on this medium. Further observation by microscope and scanning electron microscope revealed that the aerial mycelia were slender and much more branched than the substrate mycelia (Figure 1a and 1c). The aerial mycelia branched at 90 degree from the main

\begin{tabular}{|c|c|c|c|}
\hline Media & Aerial mycelium & Substrate mycelium & $\begin{array}{c}\text { Diffusible } \\
\text { pigment }\end{array}$ \\
\hline Gause's no. 1 & white & beige & - \\
\hline Kligler's no. 1 & grey & grey & - \\
\hline Czapek & grey & incarnadine & - \\
\hline Glucose asparagine & white & bright orange & - \\
\hline Glucose yeast extract & shark blue & light grey & caramel \\
\hline PDA & light crane ash & beige & - \\
\hline
\end{tabular}

Table 2: Colors of isolate HN6 on different media. "-" indicates no diffusible pigment produced.
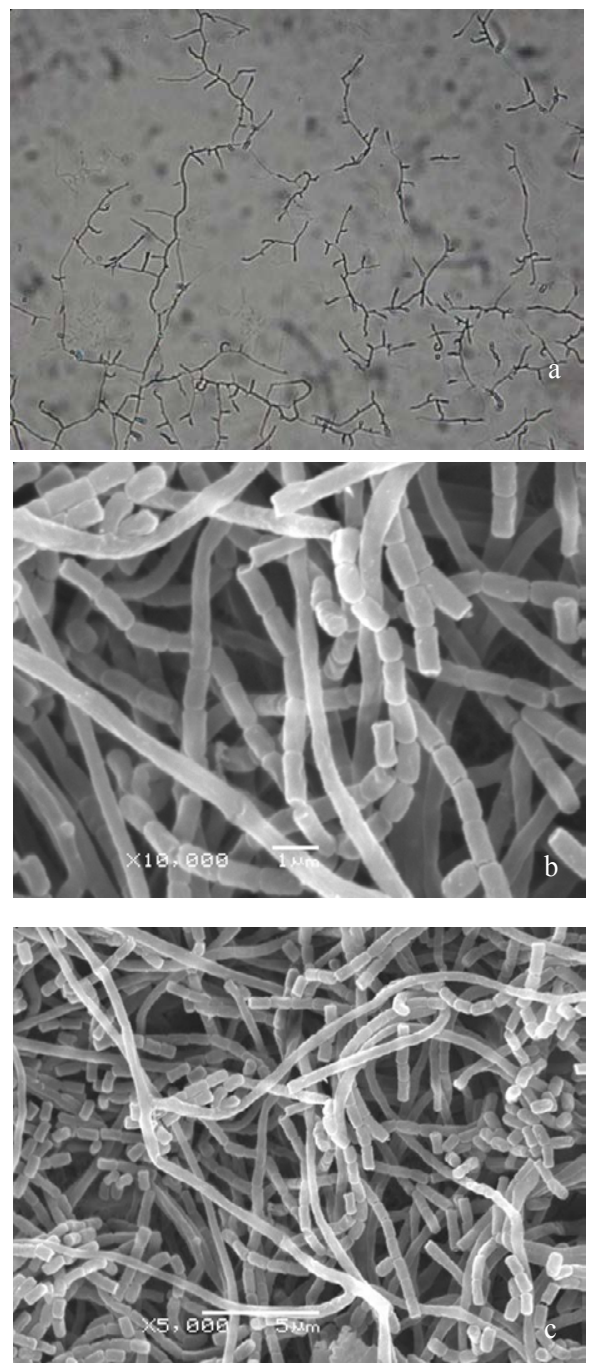

Figure 1: Microscopy and scanning electron microscopy of HN6. (a) Aerial mycelia (microscope 10×40). (b) Spore chain (electron microscope). (c) Aerial mycelia (electron microscope).

\begin{tabular}{|c|c|c|c|}
\hline Tests & Results & Tests & Results \\
\hline Starch hydrolysis & ++ & L-Arabinose utilization & ++ \\
\hline Litmus milk reaction & - & Fructose utilization & ++ \\
\hline H2S production & - & Glucose utilization & ++ \\
\hline Glutin liquefaction & ++ & Galactose utilization & ++ \\
\hline Cellulose utilization & - & Rhamnose utilization & ++ \\
\hline Inositol utilization & ++ & Sucrose utilization & ++ \\
\hline Mannitol utilization & ++ & Xylose utilization & + \\
\hline
\end{tabular}

Table 3: Physiological and biochemical characteristics of HN6. "++" strongly positive; "+" positive; "-" negative.

mycelium (Figure 1a). The spore chains broke into cylindrical conidial spores after maturing (Figure 1b).

The physiological and biochemical characteristics of HN6 were tabulated in Table 3. The HN6 isolate was able to hydrolyze starch and liquefy glutin. It could fully utilize fructose, inositol, $L$-arabinos, mannitol, rhamnose, sucrose, glucose and galactose as the carbon source. The HN6 isolate could partially utilize xylose, and not able to utilize cellulose. It could not react with litmus milk, nor decompose the sulfur-containing amino acid to $\mathrm{H}_{2} \mathrm{~S}$. The morphological, physiological and biochemical characteristics of HN6 indicated that it shared the characteristic features of the genus Streptomyces. The cellulose TLC analysis showed that the cell wall of HN6 belonged to type I, and that its whole cell sugar belonged to type C.

\section{Cloning and sequencing of HN6 16S rRNA gene and its phylogenetic analysis}

To further classify HN6 isolate, its 16S rRNA gene was PCRamplified and the $1422 \mathrm{bp}$-long PCR fragment was sequenced. The sequence was deposited in GenBank (NCBI) with the accession number of FJ911617. The HN6 16S rRNA gene sequence was analyzed by the BLAST server of NCBI. It was confirmed that HN6 belongs to the Streptomyces species. The HN6 isolate was $99 \%$ similar to Streptomyces aureoverticillatus (AY999774). The phylogenetic tree was constructed with bootstrap values (Figure 2). A neighbor-joining tree based on the 16S rRNA gene sequences showed that HN6 occupied a phylogenetic position alongside Streptomyces aureoverticillatus (AY999774). Combining the morphological, physiological and biochemical characteristics, HN6 was determined to belong to the species of Streptomyces aureoverticillatus.

\section{Antifungal activity of HN6 methanol extract}

To further elucidate the antifungal activities of HN6, its methanol extract was tested against eight indicator pathogens by the mycelium growth rate method. Table 4 shows the regression equation values (with all correlation coefficient values $>0.95$ ) of HN6 extract against the eight indicator pathogens, indicating an ideal positive correlation. The median lethal concentration $\left(\mathrm{EC}_{50}\right)$ was less than $0.08 \mathrm{mg} / \mathrm{ml}$ to every indicator pathogen, indicating a broad spectrum antifungal activity of HN6 methanol extract. Botryodiplodia theobromae (ATCC10936) was the most sensitive to the HN6 methanol extract with an $\mathrm{EC}_{50}$ of $0.016 \mathrm{mg} / \mathrm{ml}$. Colletotrichum gloeosporioides (ATCC20358), Rhizoctonia solani (ATCC58938), Colletotrichum gloeosporioides (ATCC16330), Colletotrichum musae (ATCC96167), Corynespora cassiicola (ATCC36294), Fusarium oxysporum f. sp. cubense race 4 (ATCC76255) and Periconia circinata (ATCC32727) were also sensitive to the HN6 methanol extract with the $\mathrm{EC}_{50}$ of $0.020,0.024$, $0.025,0.027,0.053,0.073$ and $0.078 \mathrm{mg} / \mathrm{ml}$ respectively. 
Citation: Wang L, Xing M, Di R, Luo Y (2015) Isolation, Identification and Antifungal Activities of Streptomyces aureoverticillatus HN6. J Plant Pathol Microb 6: 281. doi:10.4172/2157-7471.1000281

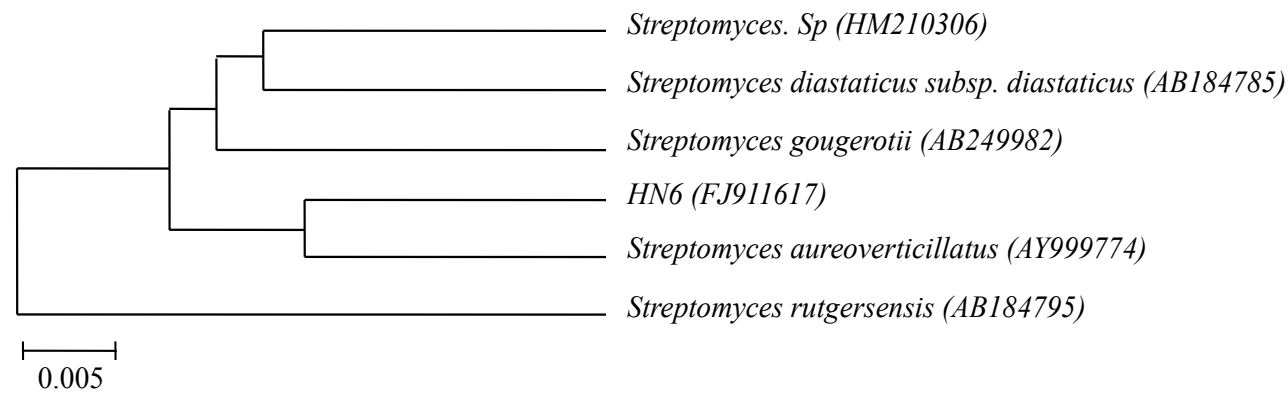

Figure 2: The phylogenetic relation of HN6 isolate (FJ911617) to Streptomyces aureoverticillatus (AY999774) and other closely related Streptomyces spp. The phylogenetic tree was constructed based on sequences of 16S rRNA genes using the neighbor-joining analysis of 1000 sampled data sets. Species with values of $>50 \%$ are shown.

\begin{tabular}{|c|c|c|c|c|}
\hline Pathogen & Regression & Correlation & EC50 & $95 \%$ confidence \\
\hline (ATCC \#) & equation $(y)$ & coefficient $(r)$ & $(\mathrm{mg} / \mathrm{ml})$ & interval $(\mathrm{mg} / \mathrm{ml})$ \\
\hline B. theobromae (10936) & $11.26+3.48 x$ & 0.960 & 0.016 & $0.0081-0.3804$ \\
\hline C. cassiicola (36294) & $7.45+1.92 x$ & 0.991 & 0.053 & $0.0289-0.4901$ \\
\hline C. gloesporioides (16330) & $12.69+4.78 x$ & 0.961 & 0.025 & $0.0195-0.4080$ \\
\hline C. gloesporioides (20358) & $12.39+4.37 x$ & 0.950 & 0.020 & $0.0181-0.3902$ \\
\hline C. musae (96167) & $11.48+4.14 x$ & 0.956 & 0.027 & $0.0184-0.4312$ \\
\hline F. oxysporum (76255) & $14.71+8.93 x$ & 0.970 & 0.073 & $0.0169-0.2135$ \\
\hline P. circinata (32727) & $14.70+8.76 x$ & 0.982 & 0.078 & $0.0146-0.5312$ \\
\hline R. solani (58938) & $12.62+4.70 x$ & 0.950 & 0.024 & $0.0064-0.3725$ \\
\hline
\end{tabular}

Table 4: Antagonistic activity of HN6 methanol extract against eight indicator plant pathogens.

\section{Discussion}

The Botanical Garden of Chinese Academy of Tropical Agricultural Sciences in Hainan Province, China, is an integrated ecological system with rich biodiversities. We isolated totally 89 actinomycetes from the soil in this garden. Many isolates had inhibition zones of $0-18 \mathrm{~mm}$ against the banana Fusarium wilt causal agent FOC4. The HN6 isolate was shown to be the most inhibitive to FOC4.

The morphological, physiological and biochemical characteristics of HN6 classified it into Streptomyces spp. The 16S rRNA gene sequence classified HN6 as Streptomyces aureoverticillatus. Publications have shown that Streptomyces spp. produce valuable bioactive metabolites with broad spectrum activities such as antibacterial, antifungal, antibiotic, antiparasitic, antitumor, antiviral, insecticidal and, herbicidal [21,22]. Streptomyces aureoverticillatus isolated from a marine sediment was discovered to produce novel anticancer and anti-infection agents which are novel macrocyclic lactam secondary metabolites [23]. As far as we know, there had not been one isolate of Streptomyces aureoverticillatus that had been shown agriculturally applicable activities. There is also no publication demonstrating the antimicrobial properties of these types of macrocyclic lactam metabolites. Recently, a new actinomycete strain NA4 was isolated from a deep-sea sediment from the South China Sea [24]. NA4 was identified as Streptomyces acvourensis by morphological, physiological and phylogenetic analysis based on its 16S rRNA gene sequences [24]. NA4 was shown to be antifungal against several soil-borne plant pathogens due to its production of bafilomycins B1 and C1 [24]. Future studies are needed to characterize the secondary metabolites of HN6 isolate and its antagonistic mechanisms in order to fully extend its potential as a biocontrol agent for FOC4 and other plant pathogens.

\section{Conclusions}

A Streptomyces aureoverticillatus isolate HN6 has been isolated from soil samples on Hainan Island, China. HN6 exhibits broad spectrum antifungal activity and is strongly inhibitive to Fusarium oxysporum f. sp. cubense race 4 (FOC4), the causal agent of banana Fusarium wilt in bio-assays.

\section{Acknowledgement}

This study was funded by Hainan Applied Technology R\&D, the Demonstration Projects (ZDXM2014115), and Hainan Province Natural Science Foundation (314054)

\section{References}

1. Sun Y, Yi X, Peng M, Zeng H, Wang D, et al. (2014) Proteomics of Fusarium oxysporum race 1 and race 4 reveals enzymes involved in carbohydrate metabolism and ion transport that might play important roles in banana Fusarium wilt. PLoS One 9:e113818. doi: 10.1371/journal.pone.0113818.

2. Wen T, Huang X, Zhang J, Zhu T, Meng L, et al. (2015) Effects of water regime crop residues, and application rates on control of Fusarium oxysporum $\mathrm{f}$. $\mathrm{sp}$. cubense. J Environ Sci (China) 31: 30-7. doi: 10.1016/j.jes.2014.11.007.

3. Yang L, Sun L, Ruan X, Quu D, Chen D, et al. (2015) Development of a singletube duplex real-time fluorescence method for the rapid quantitative detection of Fusarium oxysporum f. sp. Cubense race 1 (FOC1) and race 4 (FOC4) using TaqMan probes. Crop Protection 68: 27-35.

4. Strobel G, Daisy B, Castillo U, Harper J (2004) Natural products from endophytic microorganisms. J Nat Prod 67: 257-268.

5. Fiedler HP, Bruntner C, Riedlinger J, Bull AT, Knutsen G, et al. (2008) Proximicin A, B and C, novel aminofuran antibiotic and anticancer compounds isolated from marine strains of the actinomycete Verrucosispora. J Antibiot (Tokyo) 61: 158-63.

6. Atta HM, Dabour SM, Desoukey SG (2009) Sparsomycin antibiotic production by Streptomyces sp. AZ-NIOFD1: taxonomy, fermentation, purification and biological activities. Am-Euras J Agric Environ Sci 5: 368-377.

7. Xue L, Xue Q, Chen Q, Lin C, Shen G, et al. (2013) Isolation and evaluation of rhizosphere actinomycetes with potential application for biocontrol of Verticillium wilt of cotton. Crop Protection 43: 231-240.

8. Ravikumar S, Inbaneson SJ, Uthiraselvam M, Priya SR, Ramu A, et al. (2011) 
Citation: Wang L, Xing M, Di R, Luo Y (2015) Isolation, Identification and Antifungal Activities of Streptomyces aureoverticillatus HN6. J Plant Pathol Microb 6: 281. doi:10.4172/2157-7471.1000281

Page 5 of 5

Diversity of endophytic actinomycetes from Karangkadu mangrove ecosystem and its antibacterial potential against bacterial pathogens. J Pharm Res 4: 294296.

9. Dhanasekaran D, Thajuddin N, Panneerselvam A (2009) Distribution and ecobiology of antagonistic streptomycetes from agriculture and coastal soil in Tamilnadu, India. J Cult Collect 6: 10-20.

10. Chun J, Kim SB, Oh YK, Seong CN, Lee DH, et al. (1999) Amycolatopsis thermoflava sp. nov., a novel soil actinomycete from Hainan Island, China. Int J Syst Bacteriol 49 Pt 4: 1369-1373

11. Shirling EB, Gottlieb D (1966) Methods for characterization of Streptomyces species. Int J Syst Bacteriol 16: 313-340.

12. Kelly KL (1965) A universal color language. Color Eng 3: 2-7.

13. Valan Arasu M, Duraipandiyan V, Agastian P, Ignacimuthu S (2009) In vitro antimicrobial activity of Streptomyces spp. ERI-3 isolated from Western Ghats rock soil (India). J Med Mycol 19: 22-28.

14. Balachandran C, Duraipandiyan V, Balakrishna K, Ignacimuthu S (2012) Petroleum and polycyclic aromatic hydrocarbons (PAHs) degradation and naphthalene metabolism in Streptomyces sp. (ERI-CPDA-1) isolated from oil contaminated soil. Bioresour Technol 112: 83-90.

15. Hasegawa T, Takizawa M, Tanida S (1983) A rapid analysis for chemical grouping of aerobic actinomcetes. J Gen Appl Microbiol 29: 319-322.

16. Gupta VK, Shivasharanappa N, Kumar V, Kumar A (2014) Diagnostic evaluation of serological assays and different gene based PCR for detection of Brucella melitensis in goat. Small Ruminant Res 117: 94-102.

17. Weisburg WG, Barns SM, Pelletier DA, Lane DJ (1991) 16S ribosomal DNA amplification for phylogenetic study. J Bacteriol 173: 697-703.

18. Tamura K, Dudley J, Nei M, Kumar S (2007) MEGA4: Molecular Evolutionary Genetics Analysis (MEGA) software version 4.0. Mol Biol Evol 24: 1596-1609.

19. Amadioha AC (2001) Fungicidal activity of some plant extracts against Rhizoctonia solanii in cowpea. Arch Phytopath Pflanz 33: 509-517.

20. Zhao S, Ren FE, Liu J, Qin J, Pan H (2012) Screening, identification and optimization of fermentation conditions of an antagonistic actinomycetes strain to Setosphaeria turcica (in Chinese). Acta Microbiol Sinica 50: 1228-1236.

21. Baltz RH (2008) Renaissance in antibacterial discovery from actinomycetes. Curr Opin Pharmacol 8: 557-563.

22. Liu H, Qin S, Wang Y, Li W, Zhang J (2008) Insecticidal action of Quinomycin A from Streptomyces sp KN-0647, isolated from a forest soil. World J Microbiol Biotechnol 24: 2243-2248.

23. Mitchell SS, Nicholson B, Teisan S, Lam KS, Potts BC (2004) Aureoverticillactam, a novel 22-atom macrocyclic lactam from the marine actinomycete Streptomyces aureoverticillatus. J Nat Prod 67: 1400-1402.

24. Pan HQ, Yu SY, Song CF, Wang N, Hua HM, et al. (2015) Identification and characterization of the antifungal substances of a novel Streptomyces cavourensis NA4. J Microbiol Biotechnol 25: 353-357. 